\title{
Epididymal Adenocarcinoma
}

National Cancer Institute

\section{Source}

National Cancer Institute. Epididymal Adenocarcinoma. NCI Thesaurus. Code C39957.

A rare adenocarcinoma that arises from the epididymis. It usually presents as a scrotal mass and may be associated with testicular pain. 